\title{
Entertaining Education: User Friendly Cutting Interface for Digital Textbooks
}

\author{
Gahee Kim, Hyun-Roc Yang, Kyung-Kyu Kang, and Dongho Kim \\ Soongsil University \\ 511 Sangdo-dong Dongjak-gu, South Korea \\ \{symple87, penril87, rcrookie, prof\} @magiclab.kr
}

\begin{abstract}
Nowadays, the new paradigm demands digital textbooks which contain interactive contents. Our goal is to design the digital textbook providing effective multimedia and cutting interface for interactive education. To achieve this purpose, we propose the user friendly cutting interface and interactive animation for digital textbook. This interface complemented current digital textbook interface which is mostly in text based. We will discuss effectiveness of our interface for elementary students and how much our interface gives positive effect in learning.
\end{abstract}

Keywords: Digital Textbook, 3D Object Cutting, E-learning, Edutainment, Interface.

\section{Introduction}

Nowadays, students live in different environment from older generation. Every family has computers, and students carry a cell phone every day. They are accustomed to using computer and cell-phone, and have an ability to manage a lot of information in digital. This changed environment changed a previous teaching paradigm which is based on the off-line text book. In digital learning environment, teachers use computers and projectors and students attain information through internet and multimedia contents such as video clips, animations, and virtual reality. The paper-based textbook only delivers knowledge in one direction from teacher to students. However, the digital textbook encourages students' participation to attain the knowledge by using interactive simulation method and multimedia. In this reason, the digital textbook increases student's problem solving competency [1].

Many digital textbooks are coming out and students can easily use the digital textbooks. However, most of text books are in .pdf representation of a traditional text. These e-books may have an advantage that lowers the cost of the textbook [2], but cannot fully utilize the merit of the digital textbook. If the digital text books do not utilize multimedia to give an immersive experience, it cannot overcome the limitations of conventional textbooks.

In our research, we set our goal to develop a digital textbook which teaches 'volcano and rock' in the fifth grade curriculum. We focused on providing not only rich information based on paper-based textbook but also entertaining simulation method 
which can maximize users' participation and educational effect. For example, students can observe long time process of natural phenomena such as volcano creation through 3D simulation in our digital textbook. To start volcano creating simulation the user should put magma chamber under the bedrock. We put this process on purpose to increase users' participation. Our program also provides the cutting effect to improve users' concentration by entertaining the user. The user can enjoy with this cutting method by cutting the earth and volcano in various shapes. The user can also observe the cut cross section right after cutting the earth and volcano. This gives the user information about earth and volcano's inner appearance. For this reason our cutting method provides both entertaining and educational effect. At last, our digital textbook offers rich information in text and voice.

This research is executed as a portion of 'Developing essential technology for digital textbook and u-learning revitalization' under the sponsorship of the Korean government. In this paper, we will describe how we implemented an effective digital textbook interface for the fifth grade students.

\section{Related Work}

\subsection{Digital Textbooks in Korea}

KERIS(Korea Education and Research Information Service) has started providing Korean, English, Mathematics, Music and Science digital textbooks to public elementary schools in Korea since 2007. However, the majority of these textbooks illustrates main concept of a subject in digital text format not using multimedia or animation. Even though students use the digital textbook in class, they have to study in the same way as they studied using a previous textbook. Especially, the Science digital textbook has a great potential that the user can simulate dangerous natural phenomenon such as explosion of volcano which is impossible to perform in real class room, but current digital textbook also does not support these activities. In this way, we focused on developing the Science digital textbook which supports animation that shows process of volcano explosion and interactive cutting methods which can give students immersive experience to understand concept deeply.

\subsection{Effective Animation Interface in Educational Programs}

There were questions if the use of animation in educational programs improves student's learning or not. Media researchers have concluded whether the students learn better with animation depends on how it used [3]. In the research about how animation can be used in ways to promote learner understanding of scientific explanations, it introduces seven principles for the use of animation in multimedia instruction [4]. These principles demonstrate that a proper combination between text, narration and animation is essential interface to promote students' deep learning. We developed our animation and interactive cutting methods in accordance to these principles. We provide detail description in text and voice about the volcano, and also interactive animation which is initiated by users' participation. 


\section{Interface}

\subsection{Effective Learning Interface}

\subsubsection{Content Organization Based on Paper-Based Textbook Curriculum}

KERIS defines the digital textbook as comprehensive digital learning material which contains management program such as simulation, multimedia, and evaluation methods based on previous paper-based textbook [5]. In the 'Revised Direction and Overview of Operation Guidelines for ICT Education Primary and Secondary School' KERIS also stressed the importance of curriculum utilizing education and examples should be closely related to curriculum [6].

In this reason we focused on organizing our content closely related to previous paper-based textbook curriculum 'volcano and rock'. We drew up the scenario flowchart such as Fig.1. We classified our contents into two categories, one with providing detail explanation to users and the other with enhancing users' experience. Detail explanation is necessary to learn characteristics about each volcano and volcanic zone. In contrast to this, to learn the process of volcano creation and eruption having an experience to observe this process is more efficient than obtaining knowledge in explanation. We provide interactive animation and cutting methods in our research to enable the user observe volcano creation and eruption. These interactive animation and cutting methods also encourage not only users' experience but also users' participation.

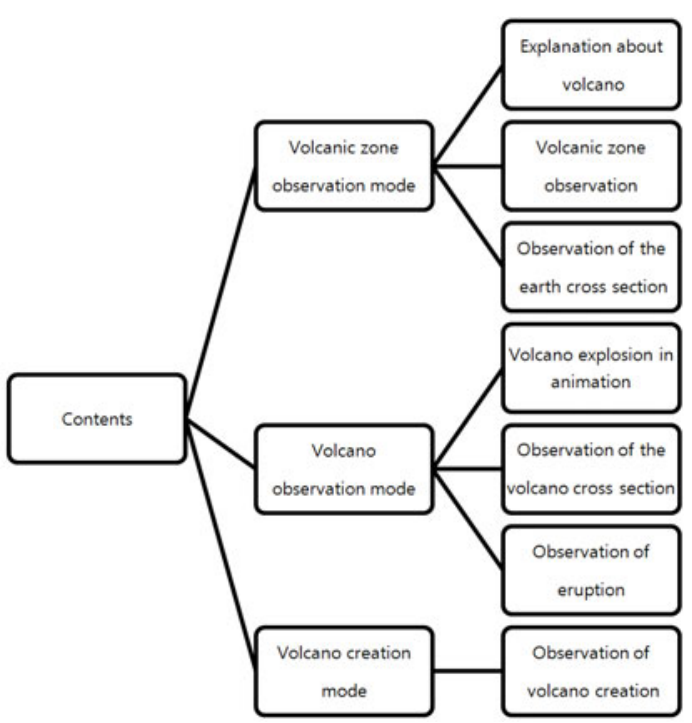

Fig. 1. Content flowchart closely related to curriculum

\subsubsection{Detail Description Based on Multimedia}

Our program illustrates a characteristic of the selected volcano and volcanic zone with both voice and text. In this way, students can attain more detail and accurate information about the volcano. The explanation in text and voice gives familiarity to users by 
enabling user to think that they are studying in previous off-line teaching method. For example, learning through the description in text is similar to study through paperbased textbooks, and hearing explanation from voice is close to learning from teachers.
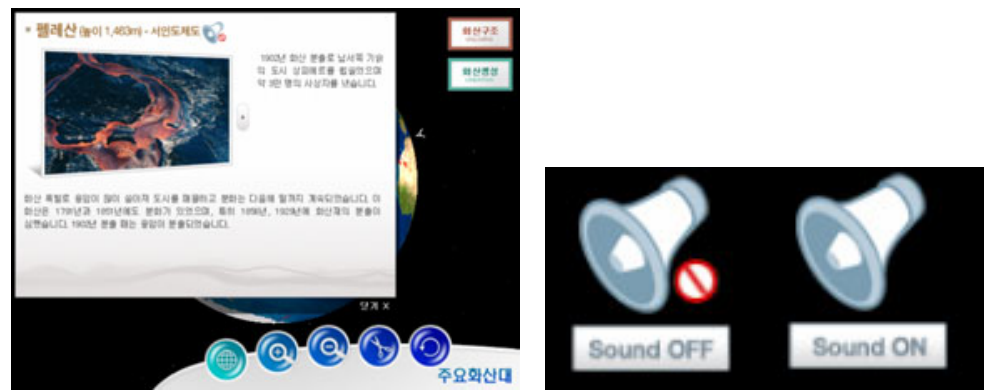

Fig. 2. Explanation on the selected volcano in text and voice

\subsection{User Friendly Interface}

\subsubsection{Encouraging Users to Entertain Our Program: Interactive Cutting Effect}

Since the users of our program are elementary students, it is very important to have an entertaining activity in our program. This fun activity will concentrate users' attention and encourage them to focus on our program for a long time. In this reason, we developed our interactive cutting method. This method not only entertains the user but also give a lesson about inside appearance of the earth and volcano. In the interactive cutting method, the user is able to cut the earth and volcano by themselves with straight and curve strokes. To use this function in our program, the user should select the cutting mode first, and cut the earth and volcano by drawing a line with a tablet pen or a mouse. The user can have fun with cutting in various shapes and enjoy observing the result of the various cut cross sections. Fig. 3 shows the cut cross section of the earth and volcano which are cut by straight and curve strokes. This interesting cut cross section is generated automatically right after the user cut the earth and volcano.
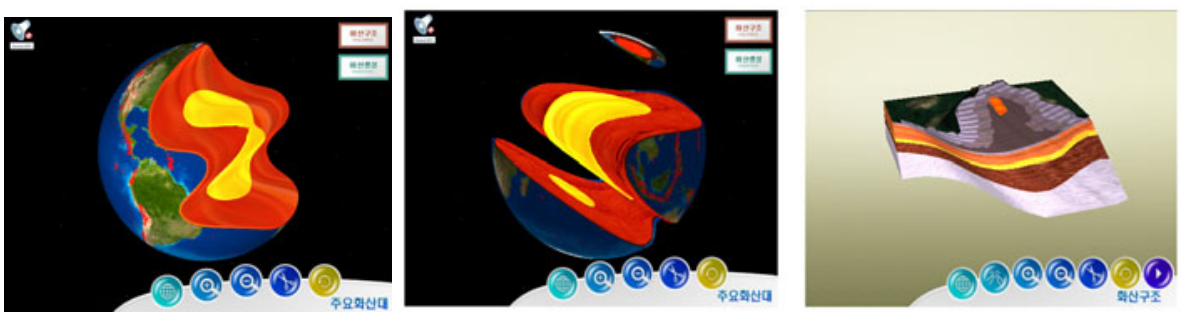

Fig. 3. Cut cross section of the earth and volcano in various shapes 


\subsubsection{Intuitive Manipulating Interface: Tablet Pen and Manipulating Panel}

\section{Tablet pen}

We used a tablet pen as a stroke manipulating interface because this can give the user more intuitive sensing than a mouse. The user usually uses a pen when they study in a traditional way, so using the tablet pen also can give familiarity to users. The intuition and familiarity encourage the user to participate in the program more easily.

\section{Manipulating panel}

Our program also has intuitive manipulating interface such as Fig.4. Because our users are elementary students, we made easy-to-understand thumbnails as a manipulating panel. Our program provides magnification/minification, cutting and rotation methods as default methods. The user can cut the earth and volcano by pushing a sizzle thumbnail button, and observe the cut cross section closely by rotating and magnifying/minifying the cross section. When the user wants to watch simulation in animation, the user selects a play button thumbnail.

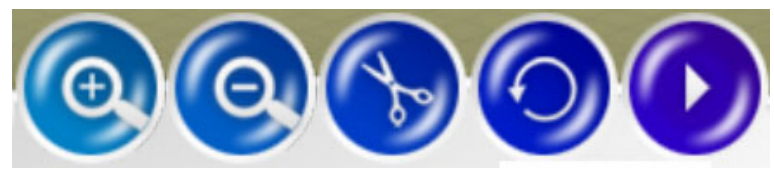

Fig. 4. Intuitive manipulating panel

\subsubsection{Increasing the User Participation: Interactive Animation}

When students push the button on the top right, the mode chances to the volcano observation mode where we can observe the volcano. In this mode the user can observe the process of volcano eruption and creation in animation.

The user can watch Fig.5, volcano eruption by pushing the play button in volcano observation mode.
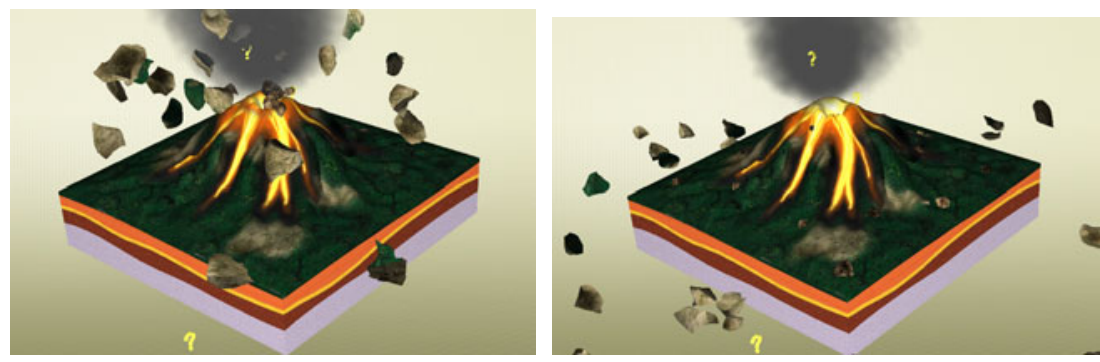

Fig. 5. Volcano eruption in animation

When the user pushes the volcano creation button, the mode is changed to the volcano creation mode. This mode enables the user to observe the process of the volcano creation. Fig. 6 shows the volcano creation mode. To observe the volcano creation in animation the user should put magma chamber under the bedrock before pushing start 
button. This process not only encourages user's participation but also gives a lesson that magma is required to generate volcano. After setting the magma chamber under the bedrock the user pushes play button to start the volcano creating animation. If the user put one magma chamber, the process of volcano creation goes on such as Fig.6(c). The more users put magma chamber under the bedrock, the bigger volcano creates such as Fig.6(d).

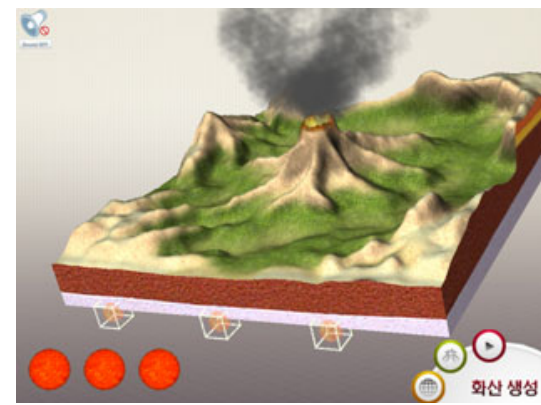

(a)

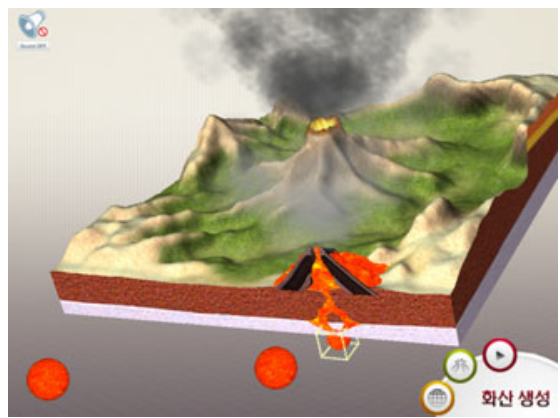

(c)

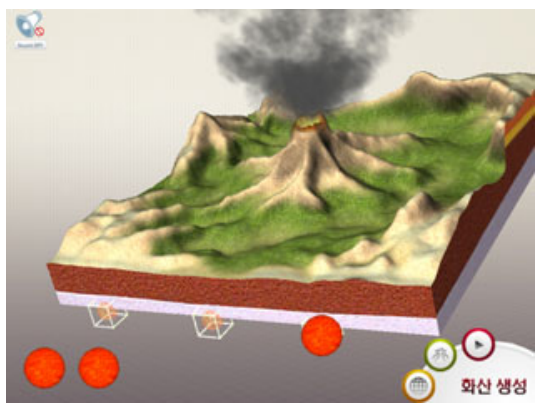

(b)

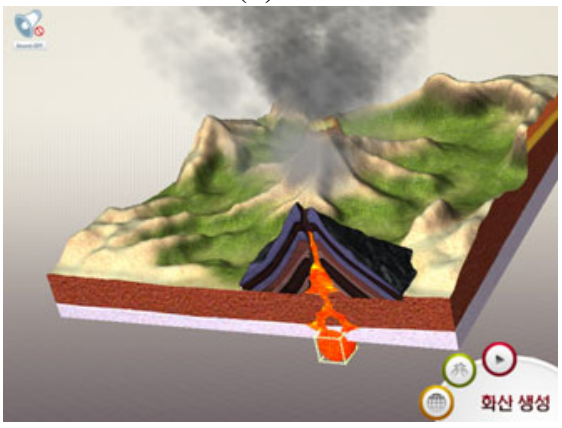

(d)

Fig. 6. Volcano creating process in animation

\section{Result}

\subsection{Cutting Performance Analysis}

The time takes to cut the object is proportion to the number of polygons. We conducted this experiment on Intel Core2Duo 6600 CPU and 4GB Ram. The earth model consists of 14,409 polygons and the average time to cut the object is $631 \mathrm{~ms}$. The Volcano model consists of 29,119 polygons and the average time to cut the object is $945 \mathrm{~ms}$.

\subsection{Trial Service Result}

We conducted a trial service at one of the elementary schools in Daejeon, Korea. 26 elementary school students and 3 teachers participated in the service. After this trial 
service, we gave our questionnaire to students and teachers. This questionnaire is made based on the research about measuring the effectiveness of digital textbook [7]. We focused on estimating participants' educational achievement by using our digital textbook compare to previous textbook. We made 13 questions and categorized these questions into three categories such as interface, educational aspect, and satisfaction to previous textbook. The score range is set from 1 to 5 . The participants gave 1 for very poor score and 5 for very satisfied score.

In the interface question we asked about the effectiveness of our cutting method, and whether it worked properly or not. We also asked if the manipulation of our digital textbook was easy to the participants. As shown in Fig.7, the participants show high satisfaction in our interface. They replied that the cutting method stimulated their curiosity, so they could participate in our program more actively. Also the thumbnail of our manipulation panel helped them to figure out the way to handle our program more intuitively.

The participants also show very satisfactory result in educational effect. In this question we concentrated on estimating the participants' understanding about 'volcano and rock' through our digital textbook. The participants replied that the animation was really effective to understand the process of volcano creation. Also they said the process that the user looks through the earth and selects the volcano they want to attain information was very helpful. This self-directed learning encourages the user to study more interactively and actively.

The average score of satisfaction compare to previous textbook is lower than other options. To complement the weak point, more interesting and entertaining aspects such as using augmented or virtual reality need to be added.

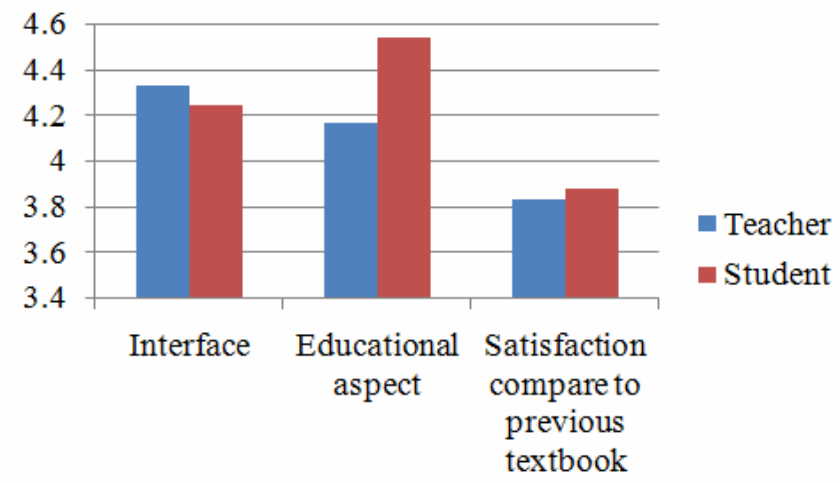

Fig. 7. Satisfaction to our system

\section{Conclusion}

In this paper, we introduced the user friendly cutting interface for digital textbook. This digital textbook teaches about 'volcano and rocks' content which is for fifth grade elementary school students. We attracted the users by providing cutting method and interactive animation. Our digital textbook also offers enrich information closely 
relate to previous paper-based textbook curriculum. This content will be serviced to the elementary students throughout the nation and the validity of application has been verified by the trial service on section 5.2. If the technology tool for encouraging interactivity such as augmented or virtual reality is added, the more effective educational content will be possible.

\section{References}

1. Song, H.D., Park, J.H.: Effects of Types of Digital Textbook Use and Levels of Academic Achievement on Learning Outcomes -from Instructional Guidance Perspective. Korean Association for Educational Information and Media 18, 29-46 (2009)

2. Kim, H.J., Seo, S.M.: A Tendency of Open Textbook in United States and Free Digital Textbook Initiative in California. KERIS Issue Report, RM 2009-36 (2009)

3. Mayer, R.E.: Multimedia learning: Are we asking the right questions? Educ. Psychol. 32, 119 (1997)

4. Mayer, R.E., Moreno, R.: Animation as an Aid to Multimedia Learning. Educ. Psychol. Review 14, 87-99 (2002)

5. Kim, J.E.: User Interface Design Research Based on the Digital Textbook Development. Master's thesis, Hanyang University (2008)

6. Kim, S.-M.: Revised Direction and Overview of Operation Guidelines for ICT Education in Primary and Secondary Schools. J. KERIS. Biol. 8, 6-8 (2006)

7. Yeon, K.-N.: Measuring the Effectiveness of Digital-Textbook in U-Learning Environments. Master's thesis, Donggook University (2007) 